\title{
Local Anesthesia in Pediatric Dentistry-How Much is Enough?
}

\author{
Eliyahu Mass*, Yael Palmon and Uri Zilberman
}

Pediatric Dental Unit, Barzilai Medical University Center, Ashkelon, Israel

*Corresponding author: Eliyahu Mass, Pediatric Dental Unit, Barzilai Medical University Center, 2nd Hahistadrut st., 7830604, Ashkelon, Israel, Tel: 08-6745555; Email: Samile8@gmail.com

Received date: March 22, 2018; Accepted date: March 28, 2018; Published date: April 04, 2018

Copyright: (c) 2018 Mass E, et al. This is an open-access article distributed under the terms of the Creative Commons Attribution License, which permits unrestricted use, distribution, and reproduction in any medium, provided the original author and source are credited.

\section{Abstract}

Aim: To evaluate the doses of local anesthesia (LA) during routine dental treatment of children, used by specialists in pediatric dentistry (SPDs), residents in pediatric dentistry (RPDs) and general practitioners (GPs) and suggest recommendations for using minimal doses.

Study design: A prospective research. 120 LA cartridges were collected after provided dental treatment of children by 4 specialists (SPD-55 cartridges), 5 residents in pediatric dentistry (RPD-43 cartridges) and 3 general practitioners (GPs-22 cartridges). The doses of the used solution were measured by deducting the remains in the cartridge from the original $1.8 \mathrm{ml}$.

Results: A significantly lower dose of LA solution was used by specialists and residents compared to GPs, $(0.786 / 0.746 \mathrm{ml} \pm 0.4 \mathrm{Vs} .1 .65 \mathrm{ml} \pm 0.3, \mathrm{P}<0.001)$.

Discussion: LA guidelines intend to achieve optimal effect, increase safety and reduce side effects. Various dentists have different training and experience, as well as personality and habits, which may affect their use of LA. This prospective study evaluated these factors.

Conclusions: The dentist training is a valuable predictor for the LA dose being injected to a child during dental treatment. The mean dose used in the study by specialists and residents was less than half compared to GPs, but effective enough for successful dental treatment, regardless of the number of treated teeth, the site, the type of the treatment and the patient's age. We suggest increasing the awareness of using minimal effective dose of LA in pediatric dentistry.

Keywords Pediatric dentistry; Local anaesthesia; Lidocaine; Mepivacaine; Dental treatment

\section{Introduction}

Pain prevention in pediatric dentistry is crucial for achieving positive experience of a child during dental treatment, building trust and cooperation and establishing a compliant dental adult. One of the main methods to prevent pain is local anesthesia [1-3].

Local anesthesia is achieved by injecting a chemical that diffuses in tissue, reaches nerve cells, binds to receptors located on the cell membrane and causes a temporary blockage of the sensory nerve conduction at the injection site [3-5]. The amount of injected material can influence the onset, duration, manifestations of toxicity and side effects of anesthesia during and after treatment.

The time before the onset and the duration of anesthesia are influenced by the specific tissue reaction to the injected solution $[3,5]$, the amount injected [6,7], the type of the local anesthetic solution [8], the individual reaction of the patient, the anatomical variations and the injection technique $[3,9]$.

Toxicity of local anesthetic substance develops when the level of the substance in the blood is higher than permitted. The causes of toxicity include: injecting into blood vessels, injecting too quickly, or injecting a larger amount of solution than allowed $[3,4,10,11]$. The toxicity is diagnosed by the suppression of the central and cardiovascular nervous system, with a range of symptoms including mild tremor, dizziness and paralysis until tonic-clonic contractions and a slight decrease in blood pressure and cardiac output $[3,9]$.

Postoperative side effects include injury of soft oral tissues due to biting post treatment and it is most common in children and physically or mentally handicapped [12]. To prevent this, it is recommended to provide local anesthesia for as short time as possible $[3,8]$.

In adults, there is a recommendation for effective minimum doses according to the different anesthesia techniques and dental procedures [3]. In children, anatomy, physiology, and metabolism are different, which requires different recommendations $[3,5]$.

The logic behind the assumption to use a minimal amount of anesthetic solution allowing treatment of children includes:

- Smaller general body mass and blood volume in children than in adults. Therefore, a reduced amount of material may reach the level of toxicity [5-7].

- The numbness after injection of local anesthetic in children is stressful [13-15]. Therefore, a minimal amount should be used in order to reduce the chance of soft tissue damage following a bite or lip chewing $[12,16,17]$.

The question is how much is effective? The answer is not clear. Insufficient anesthesia may affect the cooperation of the child and his 
behavior during and after treatment $[6,7,18]$. The pediatric literature showed extensive documentation of toxicity following doses that were too high [3,5,19-26], but for the minimum amount, there are no clear guidelines or recommendations [12].

The aim of the study was to establish current situation by:

- Analyzing prospectively the amount of local anesthetic solution injected by specialists and residents in pediatric dentistry and to compare it to general practitioners that treat children on a daily basis.

- Correlating between the dental procedures performed and the amount of local anesthetic solution needed.

\section{Materials and Methods}

Twelve dentists that treat children on a daily basis were included in the research: 4 specialists in pediatric dentistry (SPDs), 5 residents in pediatric dentistry (RPDs) and 3 general practitioners (GPs). Each dentist filled a questionnaire containing the age of the child, the treatment performed and the post-operative symptoms. The local anesthetic cartridge was attached to each questionnaire.

Only treatments of healthy children were included. 8-24 hours after treatment a dental assistant called the parents and interviewed them regarding the post-operative symptoms. The period of the research was 12 months.

The amount of local anesthetic solution injected was calculated by reducing the amount that remained in the cartridge from the basic 1.8 $\mathrm{ml}$.

Statistical analyses included uni-variate ANOVA to determine the effect of kind of local anesthesia (local infiltration Vs mandibular block), the treatment performed, gender and age of the patient, use of inhaled sedation, use of topical anesthesia, and training of the dentist on the amount of local anesthetic solution injected. The results were significantly different if $\mathrm{P}$ value was $<0.05$.

\section{Results}

Local anesthesia for dental treatment in children is one of the most important steps for achieving cooperative behavior during treatment and for positive reaction after treatment. There are no specific guidelines regarding the minimal amount of local anesthesia solution to be injected in children. We know the maximal amount to be injected by weight and we know that the success rate of good anesthesia differs with regards to the jaw to be treated and the injection technique used $[18,27]$. The maximal amount of injected solution is well established by weight and the success rate of good anesthesia differs with regards to the jaw to be treated and the injection technique used [18,27]. The amount of local anesthetic solution injected has to be suitable to complete the treatment in a positive way and to reduce the time of post-treatment numbness, in order to minimize the possibility of selfinducted trauma [27]. For local anesthesia in adults some recommendations were published: $1-1.5 \mathrm{ml}$ for mandibular block $[28,29]$ and $0.5-2.0 \mathrm{ml}$ for local infiltration [3]. In young children the bone density is reduced and the diffusion rate is higher [3] and the amount of local anesthetic solution can be reduced. SPDs and RDPs injected less than half of the amount of local anesthetic solution than GPs that treated children on a daily basis. The maximum recommended dose for $2 \%$ lidocaine with 1:100,000 epinephine to be injected is $7.0 \mathrm{mg} / \mathrm{kg}$, and for $3 \%$ mepivacaine is $6.6 \mathrm{mg} / \mathrm{kg}$. One cartridge of $2 \%$ lidocaine contains $36 \mathrm{mg}$ and should be used for children with weight of more than $5.2 \mathrm{~kg}$, while for mepivacaine 1 cartridge contains $54 \mathrm{mg}$ and the minimum weight for 1 cartridge is $8.2 \mathrm{~kg}$ [28]. The weight of the children was not reported but the youngest child was 2.5 years old and treated by a specialist using only $0.72 \mathrm{ml}$ of $2 \%$ lidocaine, so the maximum recommended dose was never reached. The use of $2 \%$ lidocaine with epinephrine in pediatric dentistry is more common for better and longer anesthesia [11,17,29]. The use of inhalation sedation reduced the amount of local anesthetic solution injected. The reports of post treatment pain were few $(22.5 \%)$, and only half of them required analgesics.

In conclusion, 3 factors influenced the amount of local anesthetic solution injected: SPDs/RPDs Vs GPs, $2 \%$ lidocaine Vs $3 \%$ mepivacaine and the use of inhalation sedation. The effect of less than half of one cartridge of local anesthetic solution was good enough for treatment of all kind of dental procedures in children. Dentists should be trained to use minimal amount of local anesthetic solution in children in order to minimize the post-operative aversive conditions and to build a good relation between the dentist and the child.

\section{References}

1. Wright GZ, Weinberger SJ, Marti R, Plotzke O (1991) The effectiveness of infiltration anesthesia in the mandibular primary molar region. Pediatr Dent 13: 278-283.

2. Sharaf AA (1997) Evaluation of mandibular infiltration versus block anesthesia in pediatric dentistry. ASDC J Dent Child 64: 276-281.

3. Malamed SF (1997) Handbook of Local Anesthesia, (4th edn), St. Louis: Mosby, pp: 14-15.

4. Becker DE, Reed KL (2006) Essentials of local anesthetic pharmacology. Anesth Prog 53: 98-109.

5. Ashkenazi M, Blumer S, Eli I (2005) Effectiveness of computerized delivery of intrasulcular anesthetic in primary molars. J Am Dent Assoc 136: 1418-1425.

6. Berggren U, Meynert G (1984) Dental fear and avoidance: causes, symptoms and consequences. JADA 109: 247-251.

7. Ayer WA (2005) Psychology and Dentistry: Mental Health Aspects of Patient Care, (1st edn), Haworth Press, pp: 15-34.

8. Wright JZ, Starkey PE, Gardner DE (1987) Child Management in Dentistry, (2nd edn) IOP Publishing, Bristol, pp: 120-135.

9. Ogle OE, Mahjoubi G (2012) Local anesthesia: agents, techniques, and complications. Dent Clin North Am 56: 133-145.

10. Haas DA (2002) An Update on local anesthetics in dentistry. J Can Dent Assoc 68: 546-551.

11. Aberg G, Sydnes G (1978) Studies on the duration of local anesthesia: effects of volume and concentration of a local anesthetic solution on the duration of dental infiltration anesthesia. Int J Oral Surg 7: 141-147.

12. Vreeland DL, Reader A, Beck M, Meyers W, Weaver J (1989) An evaluation of volumes and concentrations of lidocaine in human inferior alveolar nerve block. J Endod 15: 6-12.

13. Pinkham JR (2005) Pediatric Dentistry: Infancy through Adolescent. (4th edn), WB Sounders Company, pp: 89-115.

14. Koch G, Poulsen S (2001) Pediatric Dentistry- A Clinical Approach, (1st edn), Blackwell Munksgaard, Pp: 153-162.

15. Moore PA (1992) Preventing local anesthesia toxicity. J Am Dent Assoc 123: 60-64.

16. Ram D, Berson T, Moskovitz M, Efrat J (2010) Unsweetened ice popsicles impart a positive feeling and reduce self-mutilation after paediatric dental treatment with local anaesthesia. Int J Paediatr Dent 20: 382-388.

17. Cheatham BD, Primosch RE, Courts FJ (2010) A survey of local a dental treatment with local anaesthesia. Int J Paediatr Dent 20: 382-388.

18. McDonald RE, Avery DR (2004) Dentistry for the Child and Adolescent. (8th edn) St Louis,CV Mosby, pp: 270-284. 
Citation: Massir E, Palmon Y, Zilberman U (2018) Local Anesthesia in Pediatric Dentistry-How Much is Enough?. Dentistry 8: 480. doi:

19. Holst A, Crossner CG (1984) Management of dental behavior problems. A 5-year follow-up. Swed Dent J 8: 243-249.

20. Jones CM, Heidmann J, Gerrish AC (1995) Children's ratings of dental injection and treatment pain, and the influence of the time taken to administer the injection. Int J Paediatr Dent 5: 81-85.

21. Nakai Y, Milgrom P, Mancl L, Coldwell SE, Domoto PK, et al. (2000) Effectiveness of local anesthesia in pediatric dental practice. JADA 131: 1699-1705.

22. Chen AH (1998) Toxicity and allergy to local anesthesia. J Calif Dent Assoc 26: 683-692.

23. Cannell H (1996) Evidence for safety margins of lignocaine local anaesthetics for peri-oral use. Br Dent J 181: 243-249.

24. Moore DC, Bridenbaugh LD, Thompson GE, Balfour RI, Horton WG (1997) Factors determining dosages of amide-type local anesthetic drugs. Anesthesiol 47: 263-268.
25. Weaver JM (2007) Calculating the maximum recommended dose of local anesthestic. J Calif Dent Assoc 35: 61-63.

26. American Academy of Pediatric Dentistry (2010) Guidelines on use of Local Anesthesia for Pediatric Dental Patients. Pediatr Dent 32: 156-162.

27. Brunetto PC (2008) Anesthetic efficacy of 3 volumes of lidocaine with epinephrine in maxillary infiltration anesthesia. Anesth Prog 55: 29-34.

28. Malamed SF (2013) Handbook of Local Anesthesia, (6th edn), Elsevier Mosby, pp: 58-61.

29. Corbett IP, Ramacciato JC, Groppo FC, Meechan JG (2005) A survey of local anaesthetic use among general dental practitioners in the UK attending postgraduate courses on pain control. Br Dent J 199: 784-787. 